\title{
Effects of Anesthetic Technique on Postoperative Pulmonary Metastasis in Patients Undergoing
} Laryngectomy

\author{
Xuan-Wei Huang $\mathbb{( D}^{1, *}$ \\ Xu-Dong Wang ${ }^{2, *}$ \\ Jie-Lan Lai $\mathbb{D}^{2}$ \\ Ya-Li Lu ${ }^{2}$ \\ Kun Deng ${ }^{3}$ \\ Ren-Chun Lai (iD) ${ }^{2}$ \\ 'The First Affiliated Hospital of Sun Yat- \\ Sen University, Department of \\ Anesthesiology, Guangzhou 510080, \\ People's Republic of China; ${ }^{2}$ State Key \\ Laboratory of Oncology in South China, \\ Collaborative Innovation Center for \\ Cancer Medicine, Sun Yat-Sen University \\ Cancer Center, Department of \\ Anesthesiology, Guangzhou 510060, \\ People's Republic of China; ${ }^{3}$ Xifeng \\ People's Hospital, Department of \\ Anesthesiology, Guiyang 520122, People's \\ Republic of China \\ *These authors contributed equally to \\ this work
}

This article was published in the following Dove Press journal: Cancer Management and Research

Background: Whether laryngeal cancer is directly implanted into the lungs during orotracheal intubation is still unclear. Therefore, this study aimed to find whether orotracheal intubation is an independent risk factor for postoperative pulmonary metastasis in patients undergoing laryngectomy.

Patients and Methods: Medical records from January 1, 2006, to December 31, 2016, were reviewed. According to similar propensity scores, patients who received orotracheal intubation (tracheal intubation group, $\mathrm{n}=515$ ) were matched 1:1 with those who received tracheotomy (tracheotomy group, $\mathrm{n}=326$ ) in the induction of general anesthesia. The primary outcome was postoperative pulmonary metastasis. Secondary outcomes included local recurrence, lymphatic metastasis, tracheostomal recurrence and overall survival.

Results: Between the two groups, there was no significant difference in postoperative pulmonary metastasis $(P=0.688)$, local recurrence $(P=0.215)$, lymphatic metastasis $(P=0.480)$, tracheostomal recurrence $(P=0.246)$ or all-cause death $(P=0.299)$. The primary site of cancer was an independent risk factor for pulmonary metastasis [HR $0.29,95 \%$ CI $0.13-0.68 ; P=$ 0.013 ] and local recurrence (HR 2.69, 95\% CI 1.39-5.21; $P=0.003$ ). Type of surgery (HR 3.13, 95\% CI 2.03-4.84; $P<0.001$ ) and N classification of TNM (HR 0.27, 95\% CI 0.10-0.75; $P=$ 0.012) were risk factors for local recurrence. Postoperative chemotherapy was an independent risk factor for lung metastasis (HR 7.58, 95\% CI 3.11-18.47; $P<0.001$ ) and lymphatic metastasis (HR 5.18, 95\% CI 2.57-11.91; $P<0.001$ ), and 5-year overall survival was associated with age $(P=0.028)$, clinical stage $(P<0.001)$ and postoperative chemotherapy $(P=0.003)$ but not with anesthetic technique $(P=0.473)$.

Conclusion: This retrospective study suggests that orotracheal intubation in laryngectomy is not a risk factor for postoperative pulmonary metastasis, local recurrence, lymphatic metastasis or overall survival.

Keywords: laryngectomy, lung metastasis, local recurrence, tracheal intubation, tracheotomy

\section{Background}

Laryngeal cancer is one of the most common cancers in the head and neck region. ${ }^{1,2}$ The main treatment for laryngeal squamous cell carcinoma (LSCC) is surgery, sometimes followed by radiotherapy and/or chemotherapy if the tumor is large or if high risk factors exist. ${ }^{3}$ However, a review by the American Cancer Society suggested that the overall incidence of LSCC is declining, and the 5-year survival rate has decreased from $66 \%$ to $63 \%{ }^{4}$ The main target organ of laryngeal cancer distant metastasis is the lung, followed by liver and bone metastasis. ${ }^{5}$ Metastatic disease is
Correspondence: Ren-Chun Lai Email lairch@sysucc.org.cn 
the most important cause of cancer-related death in patients after cancer surgery. Currently, in laryngeal cancer, whether the tumor is directly implanted into the lungs through the respiratory tract or metastasizes through lymph nodes or blood is still unclear. Therefore, it is of great importance to minimize the chance of postoperative pulmonary metastasis during laryngeal cancer surgery.

Inevitably, orotracheal intubation or tracheotomy is necessary to induce general anesthesia for laryngeal surgery. Intact lung mucosa has a protective effect, and tumor cells are not easy to form planting foci. However, mechanical ventilation during surgery can cause lung injury, which may be conducive to the cultivation of exfoliated tumor cells, resulting in tumor cell implantation and lung metastasis. ${ }^{6}$ During general anesthesia, immunosuppression is usually inevitable, ${ }^{7}$ especially in basic diseases that require surgical treatment, such as cancer. ${ }^{8}$ Perioperative factors including immunosuppression and anesthetic technique have been suggested to affect cancer cell survivals and metastasis. ${ }^{9,10}$ Thus, due to the specific physiological location of laryngeal cancer, tumor tissue may drop into the lungs, particularly during orotracheal intubation. Unfortunately, there is no relevant research, and thus, whether orotracheal intubation increases the risk of postoperative pulmonary metastasis is unclear.

In this study, propensity matching to balance differences in baseline characteristics was conducted and an LSCC database was reviewed to determine the causal relationship between anesthetic technique and postoperative pulmonary metastasis in LSCC, and to identify risk factors for local recurrence, lymphatic metastasis, stomal recurrence and survival rates associated with orotracheal intubation.

\section{Patients and Methods}

Considering that this was a retrospective cohort study and informed consent of participants could not be sought completely, the ethics committee of Sun Yat-sen University Cancer Center approved this study ethically and covers the privacy of the participants. Besides, the study also complied with the Declaration of Helsinki. After that, the oncology and anesthesia databases were reviewed.

By retrospectively screening the laryngeal database, anaesthesia database, electronic medical records, and follow-up status, we identified patients who had undergone partial laryngectomy or total laryngectomy for LSCC between January 1, 2006, and December 31, 2016. Among them, 882 cases undergoing partial laryngectomy or total laryngectomy were enrolled in this study. All cases were definitively diagnosed. The therapy for each patient was based on NCCN guidelines, and the tumor location, tumor node and distant metastasis status were defined on the basis of the 3rd to 6th edition of the UICC classification system and the 2 nd to 7 th edition of the AJCC staging system. Patients were excluded according to the following criteria: 1) pulmonary metastasis before surgery; 2) non-squamous cell carcinoma confirmed by postoperative pathology; and 3) lost to follow-up.

During the study period, anesthesia induction was performed with propofol $(1.5-2 \mathrm{mg} / \mathrm{kg})$ or etomidate $(0.3 \mathrm{mg} /$ $\mathrm{kg})$, fentanyl $(0.003 \mathrm{mg} / \mathrm{kg})$ or sufentanil $(0.5 \mu \mathrm{g} / \mathrm{kg})$, and cisatracurium $(0.15-0.2 \mathrm{mg} / \mathrm{kg})$. Then, anesthesia was maintained with sevoflurane (minimal alveolar concentration $=0.7-1.5)$, remifentanil $(0.05-0.15 \mu \mathrm{g} / \mathrm{kg} / \mathrm{min})$ and cisatracurium (1-2 $\mu \mathrm{g} / \mathrm{kg} / \mathrm{min}$ ). An Opioid (fentanyl) and a non-steroidal anti-inflammatory drug (flurbiprofen or parecoxib) were always used for postoperative analgesia. Whether orotracheal intubation was employed depended on the condition of the tumor, especially the tumor size. In addition, in patients who were in an advanced stage, the preference of the surgeons and anesthesiologists play a role. In the tracheotomy group, a tracheotomy was performed before induction of general anesthesia, via local infiltration with $2 \%$ lidocaine for anesthesia. For patients in the tracheal intubation group, laryngoscopic orotracheal intubation was implemented following anesthesia induction. In both groups, male patients were intubated with a 7.0 tracheal tube and female patients with a 6.5 tracheal tube. The opioid dosage was converted into an equianalgesic (morphine dosage) to compare the two groups.

Patients at Sun Yat-Sen University Cancer Center had their first clinical and radiological evaluation 1 month after the final treatment, then every 3 months for the first year, 2-3 times in the second and third years, and annually thereafter. Pulmonary metastasis was defined by histological verification or imaging (computerized tomography or enhanced computerized tomography), with metastatic tumor manifesting as single or multiple nodules of different sizes scattered in the lungs that gradually grew or increased with time, and some were accompanied by pleural effusion. Clinical and histological verification of LSCC more than three months after the initial treatment was defined as local recurrence, whereas LSCC diagnosed within three months of primary therapy was defined as residual tumor. ${ }^{5}$ Meanwhile, we defined lymph node metastasis as growing lymph nodes identified by color doppler ultrasonography or computerized tomography, ${ }^{11}$ and some of the samples were also diagnosed via pathology. Death was considered to be related to LSCC when patients died during treatment, or within 30 postoperative days, or if medical records or the death 


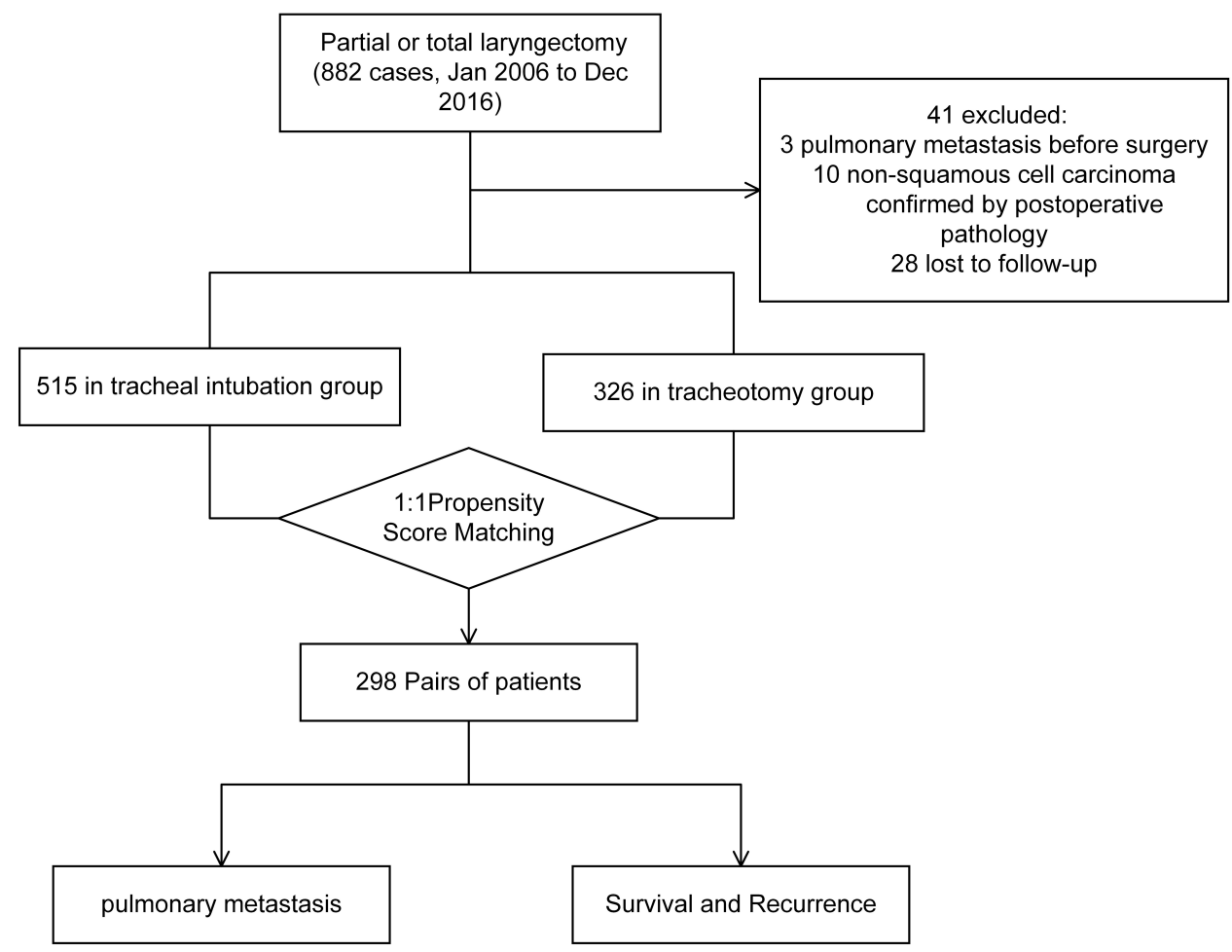

Figure I The selection and matching process. During January I, 2006, to December 31, 2016, 882 cases undergoing partial laryngectomy or total laryngectomy were enrolled in this study. According to the standard of exclusion, participants were divided into tracheal intubation group and tracheotomy group. The two groups were matched I:I according to similar propensity scores, then 298 pairs of patients were analyzed finally.

certificate documented laryngeal cancer as the underlying cause of death. Generally, a patient's status and cause of death were confirmed from death certificates or follow-up data. Postoperative complications were defined as surgical incision bleeding, laryngeal fistula or subcutaneous emphysema.

Gender, age, height, weight, body mass index (BMI), information on smoking and alcohol use and previous history of disease were documented for each patient in the hospital information system. Historical diseases were defined according to previously described definitions, ${ }^{12}$ and included cardiac disease, chronic kidney disease, hypertension, diabetes mellitus, and a history of other cancer types. In addition, patients in the tracheal intubation group were matched 1:1 with those in the tracheotomy group, considering operative time, $\mathrm{T}$ classification (T1/2, $\mathrm{T} 3 / 4$ ), clinical stage (1-4), type of surgery (partial laryngectomy, total laryngectomy), preoperative radiotherapy (yes, no), and postoperative chemotherapy (yes, no).

\section{Statistical Analysis}

Descriptive statistics are presented as percentages, continuous variables are presented as the mean \pm standard deviation, and values were compared with a $\chi 2$-test and a two-sample $t$ test. All imbalanced variables with a significance level of $P<0.05$ on a $\chi 2$-test or $t$ test were used to calculate the propensity score through logistic regression. According to Dr. Austin's ${ }^{13}$ recommendations, the nearest-neighbor matching method with a caliper of 0.02 ( 0.2 of standard deviation) was used to perform a one-to-one match without replacement. KaplanMeier curves, Log rank test and hazards regression were used to analyze pulmonary metastasis, local recurrence, lymphatic metastasis and overall survival. In addition, the clinical significance and the sample capacity were considered. Cox regression was used to analyze the risk factors that showed a $P$ value $<0.1$ in Kaplan-Meier curves of metastasis and recurrence. The results are expressed as the $95 \%$ CI. Statistical significance was set at $P<0.05$, and all tests were two-sided. All statistical analyses were performed with SPSS statistics 24.0 software for Windows (SPSS Inc, Chicago, IL, USA).

\section{Results}

\section{Baseline of Patients' Characteristics}

The selection and matching process for this review is showed in Figure 1. Among 841 participants, 515 patients 
were orotracheally intubated, and the other 326 received a tracheotomy. The two groups were matched 1:1 according to similar propensity scores, which were estimated based on anesthesia time ( $\mathrm{P}=0.03)$, T classification $(\mathrm{P}<$ 0.001), clinical stage $(\mathrm{P}<0.001)$, type of surgery $(\mathrm{P}<$ $0.001)$, preoperative radiotherapy $(\mathrm{P}=0.031)$, and postoperative chemotherapy ( $\mathrm{P}=0.004)$, finally producing 298 patients in each group. The baseline characteristics and clinicopathological characteristics of the two groups, before and after matching, are summarized in Table 1.

\section{Anesthetic Technique and Outcomes}

The total incidence of pulmonary metastasis in the selected patients was $5 \%$, and after the matching, the total incidence of pulmonary metastasis was $4.4 \%$. The incidence of pulmonary metastasis in tracheal intubation group was $4.7 \%$, which was higher than that in the tracheotomy group (4\%), but the difference did not reach statistical significance $(P=0.688)$. In addition, the incidence of local recurrence $(22.1 \%)$, lymphatic metastasis $(5 \%)$, tracheostomal recurrence $(0 \%)$, postoperative complications $(6 \%)$ and all-cause death $(23.2 \%)$ in the tracheal intubation group was lower than that in the tracheotomy group $(26.5 \%, 6.4 \%, 1 \%, 7 \%, 27.2 \%)$; however, again, the difference was not significantly.

\section{Risk Factors for Pulmonary Metastasis}

Figure 2 and Table 2 clearly show that orotracheal intubation may not be an independent risk factor for lung metastasis $(\mathrm{P}=0.333)$, but primary site of cancer (hazard ratio $[\mathrm{HR}]=0.29,95 \%$ confidence interval $[95 \% \mathrm{CI}] 0.13-0.68$, $\mathrm{P}=0.013)$ and postoperative chemotherapy $(\mathrm{HR}=7.58$, 95\% CI 3.11-18.47, $\mathrm{P}<0.001)$ were independent risk factors for postoperative pulmonary metastasis.

\section{Risk Factors for Local Recurrence, Lymphatic Metastasis and Tracheostomal Recurrence}

Table 3 summarizes the risk factors for local recurrence. Type of surgery (total laryngectomy HR $=3.13,95 \% \mathrm{CI}$ 2.03-4.84, $P<0.001$ ), N classification (N [2] HR $=0.27$, 95\% CI $0.10-0.75, P=0.012$ ) and primary site of cancer (glottic laryngeal $\mathrm{HR}=2.69,95 \%$ CI 1.39-5.21, $\mathrm{P}=0.003$ ) were independent risk factors for local recurrence. From Table 4, BMI was found to have statistical significance in univariable analysis $(P=0.007)$ and in multivariable analysis $(P=0.007)$. According to World
Health Organization, ${ }^{12}$ BMI was classified as follows: normal weight $(18.5 \leq \mathrm{BMI}<25.0 \mathrm{~kg} / \mathrm{m} 2)$, underweight (BMI $\leq 18.5 \mathrm{~kg} / \mathrm{m} 2)$, overweight $(25.0 \leq \mathrm{BMI}<30.0 \mathrm{~kg} /$ $\mathrm{m} 2$ ), and obese (BMI $\geq 30.0 \mathrm{~kg} / \mathrm{m} 2)$. However, considering that only 4 participants had BMI $\geq 30.0 \mathrm{~kg} / \mathrm{m} 2$, we classified these patients as overweight. After classifying the BMI of patients, BMI was found to not be a significant factor $(\mathrm{P}=0.774)$. Therefore, the only independent risk factor for lymphatic metastasis was postoperative chemotherapy $(\mathrm{HR}=5.18,95 \%$ CI $2.57-11.91, \mathrm{P}<0.001)$. After the two groups were matched 1:1 according to similar propensity scores, there were only 3 patients in tracheotomy group had tracheostomal recurrence while there were none in the other group $(\mathrm{P}=0.249)$. Considering this situation, it was no surprise that independent risk factors for tracheostomal recurrence could not be found in this study.

\section{Risk Factors for Survival}

The 5-year overall survival in the tracheal intubation group and tracheotomy group was $61.4 \%$ (95\% CI $0.53-0.69)$ and $65.3 \%$ (95\% CI $0.58-0.73$, log-rank $\mathrm{P}=0.473)$, respectively (see Figure 3A). Nevertheless, age $(\mathrm{P}=$ 0.028 , see Figure $3 \mathrm{~B})$, clinical stage $(\mathrm{P}<0.001$, see Figure $3 \mathrm{C})$ and postoperative chemotherapy $(\mathrm{P}=0.003$, see Figure 3D) showed significance for survival.

\section{Discussion}

The death of most laryngeal cancer patients is due to distant metastasis and the lung is the most common site of distant metastasis in laryngeal cancer. ${ }^{14}$ Currently, in laryngeal cancer, whether the tumor is directly implanted in the lungs through the respiratory tract or metastasize via lymph nodes or blood is still unclear. The mechanism may be related to genes, molecular proteins, hematogenous metastasis and implantation metastasis. Implantation metastasis has been found to occur via enterocelia spread in ovarian cancer, ${ }^{15}$ and spread of colon cancer through colonoscopic biopsy sites or laparoscopic port sites has been reported. ${ }^{16}$ Previous studies have also reported occasional metastasis after a needle biopsy for a malignant lung tumor $^{17}$ or after a bronchoscopic procedure. ${ }^{18}$ In orotracheal intubation, a tube must be passed through the tumor, leading to the possibility that tumors are brought into the lower respiratory tract. However, this possibility has not yet been confirmed. In our study, anesthetic technique had no effect on postoperative pulmonary metastasis. Orotracheal intubation 
Table I Distribution of Patient Characteristics in the Tracheal Intubation and Tracheotomy Groups, Before and After Propensity Score Matching

\begin{tabular}{|c|c|c|c|c|c|c|}
\hline \multirow[t]{2}{*}{ Characteristics } & \multicolumn{2}{|l|}{ Before Matching } & \multirow[t]{2}{*}{$P$ value } & \multicolumn{2}{|l|}{ After Matching } & \multirow[t]{2}{*}{$P$ value } \\
\hline & $\begin{array}{l}\text { Tracheal Intubation } \\
\text { Group }\end{array}$ & $\begin{array}{l}\text { Tracheotomy } \\
\text { Group }\end{array}$ & & $\begin{array}{l}\text { Tracheal Intubation } \\
\text { Group }\end{array}$ & $\begin{array}{l}\text { Tracheotomy } \\
\text { Group }\end{array}$ & \\
\hline Total & 515 & 326 & & 298 & 298 & \\
\hline Age & $60.17 \pm 8.9$ & $60.93 \pm 9.4$ & 0.248 & $60.38 \pm 9.5$ & $60.79 \pm 8.8$ & 0.623 \\
\hline Age $<60(y r)$ & $252(49)$ & $15 \mid(46)$ & 0.479 & $137(46)$ & $138(46)$ & 1.000 \\
\hline Male & $500(97)$ & $316(97)$ & 0.897 & $288(96)$ & $289(97)$ & 0.816 \\
\hline BMI $\left(\mathrm{kg} / \mathrm{m}^{2}\right)$ & $21.8 \pm 3.1$ & $22.0 \pm 3.2$ & 0.255 & $21.5 \pm 3.1$ & $21.9 \pm 3.1$ & 0.752 \\
\hline Smoking index & 531 & 604 & 0.058 & 591 & 552 & 0.896 \\
\hline Alcohol intake & $135(26)$ & $92(28)$ & 0.523 & $77(25)$ & $84(28)$ & 0.518 \\
\hline Hypertension & $88(17)$ & $48(14)$ & 0.364 & $50(16)$ & $44(15)$ & 0.500 \\
\hline Diabetes & $29(6)$ & $16(5)$ & 0.650 & $14(5)$ & $15(5)$ & 0.849 \\
\hline Cardiac disease & $16(3)$ & $10(3)$ & 0.974 & $13(4)$ & $10(3)$ & 0.523 \\
\hline \multicolumn{7}{|l|}{ ASA } \\
\hline 2 & $237(46)$ & 137 (42) & 0.178 & $132(44)$ & $\mid 23(4 \mid)$ & 0.524 \\
\hline 3 & $257(50)$ & $|8|(56)$ & & $156(52)$ & $168(56)$ & \\
\hline 4 & $21(4)$ & $8(2)$ & & $10(4)$ & $7(3)$ & \\
\hline Cancer history & $24(5)$ & $8(3)$ & 0.103 & $14(5)$ & $6(2)$ & 0.069 \\
\hline $\begin{array}{l}\text { Opioids } \\
\text { (morphine, mg) }\end{array}$ & $62.3 \pm 1.1$ & $74.1 \pm 1.6$ & $0.007^{*}$ & $70.4 \pm 1.5$ & $70.9 \pm 1.6$ & 0.436 \\
\hline \multicolumn{7}{|l|}{ Type of surgery } \\
\hline Partial laryngectomy & $247(48)$ & $89(27)$ & $<0.00 I^{*}$ & $99(33)$ & $88(30)$ & 0.332 \\
\hline Total laryngectomy & $268(52)$ & $237(73)$ & & $199(67)$ & $210(70)$ & \\
\hline Neck dissection & $27 \mid(53)$ & $190(58)$ & 0.108 & $184(62)$ & $170(57)$ & 0.243 \\
\hline Anesthesia time $(\mathrm{h})$ & $2.8 \pm 1.3$ & $3.4 \pm 1.4$ & $0.030 *$ & $3.2 \pm 1.3$ & $3.2 \pm 1.3$ & 0.914 \\
\hline Blood transfusion & $\mathrm{I}(0.2)$ & 0 & 0.426 & I $(0.3)$ & 0 & 0.317 \\
\hline \multicolumn{7}{|l|}{ Primary cite of cancer } \\
\hline Supraglottic & $104(20)$ & $78(24)$ & 0.438 & $59(20)$ & $70(24)$ & 0.505 \\
\hline Glottic & $400(78)$ & $24 I(74)$ & & $230(77)$ & $221(74)$ & \\
\hline Subglottic & II (2) & $7(2)$ & & $9(3)$ & $7(2)$ & \\
\hline \multicolumn{7}{|l|}{ Tumor Differentiation } \\
\hline Poorly differentiated & $80(16)$ & $46(14)$ & 0.755 & $47(16)$ & $39(13)$ & 0.626 \\
\hline $\begin{array}{l}\text { Moderately } \\
\text { differentiated }\end{array}$ & $289(56)$ & $181(56)$ & & $162(54)$ & $170(57)$ & \\
\hline Highly differentiated & $146(28)$ & $99(30)$ & & $89(30)$ & & \\
\hline \multicolumn{7}{|l|}{ T classification } \\
\hline I & $75(15)$ & $19(6)$ & $<0.00 I^{*}$ & $21(7)$ & $19(6)$ & 0.967 \\
\hline 2 & $159(30)$ & $79(24)$ & & $74(25)$ & $78(26)$ & \\
\hline 3 & $180(35)$ & $130(40)$ & & $113(38)$ & 114 (38) & \\
\hline 4 & $10 \mid(20)$ & $98(30)$ & & $90(30)$ & $87(30)$ & \\
\hline \multicolumn{7}{|l|}{$\mathrm{N}$ classification } \\
\hline 0 & $394(77)$ & $244(75)$ & 0.208 & $220(74)$ & $228(77)$ & 0.213 \\
\hline 1 & $51(9)$ & $44(14)$ & & $30(10)$ & $36(12)$ & \\
\hline 2 & $67(13)$ & $38(12)$ & & $46(15)$ & $34(\mathrm{II})$ & \\
\hline 3 & $3(1)$ & 0 & & $2(I)$ & 0 & \\
\hline
\end{tabular}

(Continued) 
Table I (Continued).

\begin{tabular}{|c|c|c|c|c|c|c|}
\hline \multirow[t]{2}{*}{ Characteristics } & \multicolumn{2}{|l|}{ Before Matching } & \multirow[t]{2}{*}{$P$ value } & \multicolumn{2}{|l|}{ After Matching } & \multirow[t]{2}{*}{$P$ value } \\
\hline & $\begin{array}{l}\text { Tracheal Intubation } \\
\text { Group }\end{array}$ & $\begin{array}{l}\text { Tracheotomy } \\
\text { Group }\end{array}$ & & $\begin{array}{l}\text { Tracheal Intubation } \\
\text { Group }\end{array}$ & $\begin{array}{l}\text { Tracheotomy } \\
\text { Group }\end{array}$ & \\
\hline $\begin{array}{l}\text { Clinical stage } \\
\text { I/II } \\
\text { III/IV }\end{array}$ & $\begin{array}{l}204(40) \\
311(60)\end{array}$ & $\begin{array}{l}85(26) \\
24 I(74)\end{array}$ & $<0.00 I^{*}$ & $\begin{array}{l}85(28) \\
213(72)\end{array}$ & $\begin{array}{l}84(28) \\
214(72)\end{array}$ & 0.920 \\
\hline $\begin{array}{l}\text { Postoperative } \\
\text { complications }\end{array}$ & $23(4)$ & $22(7)$ & 0.152 & $18(6)$ & $21(7)$ & 0.619 \\
\hline $\begin{array}{l}\text { Preoperative } \\
\text { radiotherapy }\end{array}$ & $18(4)$ & $22(7)$ & $0.03 I^{*}$ & $13(4)$ & $16(5)$ & 0.568 \\
\hline $\begin{array}{l}\text { Preoperative } \\
\text { chemotherapy }\end{array}$ & $15(3)$ & $10(3)$ & 0.897 & $10(3)$ & $8(3)$ & 0.632 \\
\hline $\begin{array}{l}\text { Postoperative } \\
\text { radiotherapy }\end{array}$ & $88(17)$ & $52(16)$ & 0.666 & $62(21)$ & $45(15)$ & 0.070 \\
\hline $\begin{array}{l}\text { Postoperative } \\
\text { chemotherapy }\end{array}$ & $19(4)$ & $27(8)$ & $0.004^{*}$ & $15(5)$ & $15(5)$ & 1.000 \\
\hline
\end{tabular}

Notes: Data are the median, or number and percentage (\%), analyzed with a Fisher's exact test, $\chi 2$-test or two-sample $t$ test. $* P<0.05$ is statistically significant. Abbreviations: BMI, body mass index; ASA, American society of Anesthesiology; T classification, tumor classification of tumor, node and metastasis classification of cancer; $\mathrm{N}$ classification, node classification of tumor, node and metastasis classification of cancer.

did not increase the risk of pulmonary metastasis after laryngectomy. However, recent studies have shown a high tendency of pulmonary metastasis after laryngeal cancer surgery. ${ }^{19}$ The mechanism driving this tendency may be explained by the unique immune microenvironment of the lung. In this study, we found that anesthetic technique had no effect on local recurrence, lymphatic metastasis, postoperative complications, all-cause death or survival. These findings differed from those presented in previous studies. ${ }^{20,21}$

Our results showed that anesthesia time, history of other cancers, primary site of cancer, tumor differentiation, $\mathrm{N}$ classification, preoperative chemotherapy and postoperative chemotherapy had a significant influence on

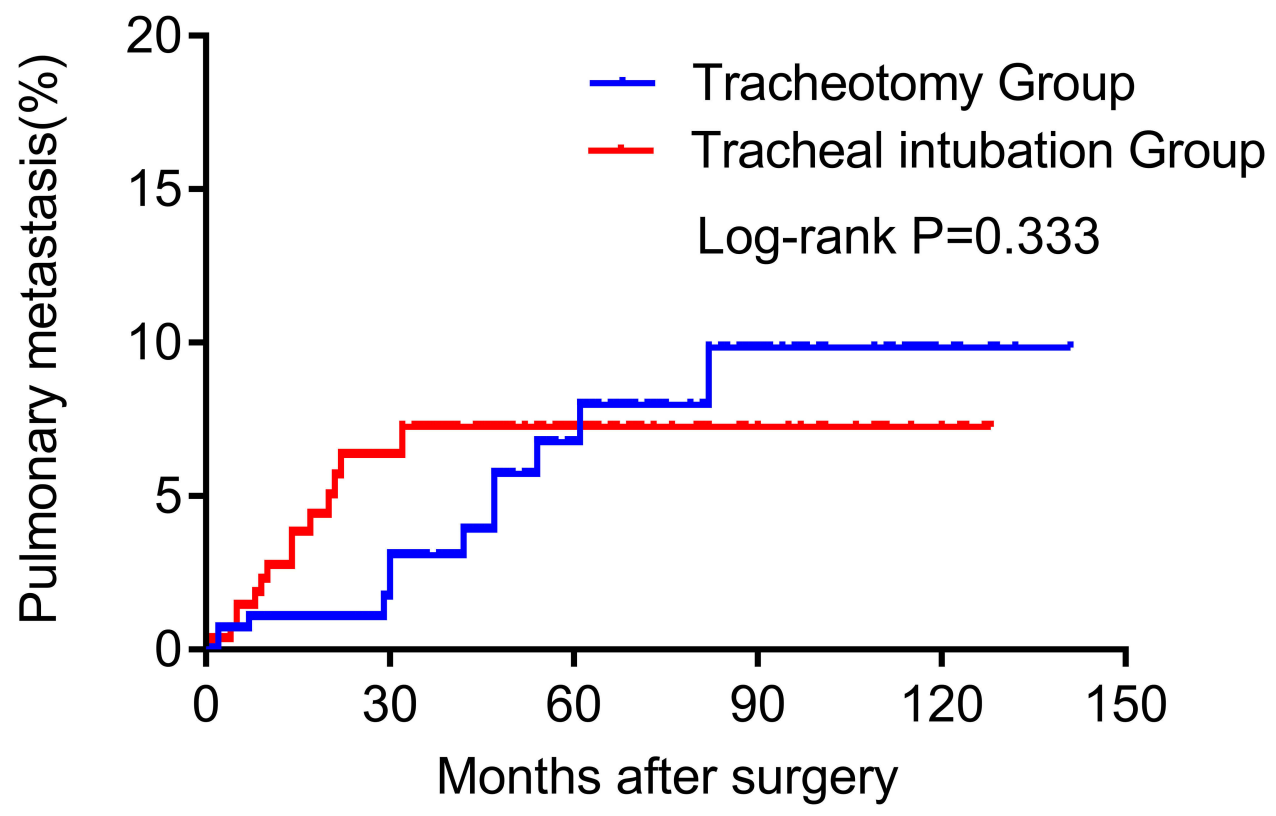

Figure 2 Cumulative incidence of pulmonary metastasis in the tracheal intubation group and tracheotomy group. A log rank test was used to analyze the effect of tracheal intubation for pulmonary metastasis in patients undergoing laryngectomy. Comparison of survival curves of two groups showed that there is no significant difference in pulmonary metastasis $(P>0.05)$. 
Table 2 Univariable and Multivariable Cox Proportional Hazard Models of Pulmonary Metastasis After Surgery for LSCC

\begin{tabular}{|c|c|c|c|c|}
\hline & \multicolumn{2}{|c|}{ Univariable Analysis } & \multicolumn{2}{|c|}{ Multivariable Analysis } \\
\hline & HR (95\% Cl) & $P$ value & HR (95\% Cl) & $P$ value \\
\hline Age $\geq 60(y r)$ & I.22 $(0.56,2.66)$ & 0.617 & & \\
\hline Gender (Female) & $0.05(0.00,483.46)$ & 0.517 & & \\
\hline BMI $\left(\mathrm{kg} / \mathrm{m}^{2}\right)$ & $0.88(0.77,1.00)$ & $0.058^{*}$ & & 0.221 \\
\hline Smoking & $1.80(0.62,5.24)$ & 0.279 & & \\
\hline Alcohol intake & $0.96(0.40,2.29)$ & 0.929 & & \\
\hline ASA & $1.16(0.53,2.56)$ & 0.715 & & \\
\hline Cancer history & $2.57(0.61,10.90)$ & 0.200 & & \\
\hline Opioids (morphine, mg) & $1.01(0.99,1.02)$ & $0.061 *$ & & 0.283 \\
\hline Types of surgery & $1.20(0.52,2.77)$ & 0.664 & & \\
\hline Neck dissection & $2.16(0.90,5.14)$ & $0.083^{*}$ & & 0.490 \\
\hline Tracheal intubation & $1.46(0.67,3.17)$ & 0.336 & & 0.264 \\
\hline Anesthesia time & $1.33(1.03,1.71)$ & $0.029 *$ & & 0.334 \\
\hline Primary site of cancer & & $0.015^{*}$ & & $0.013^{* *}$ \\
\hline Supraglottic & Reference & & Reference & \\
\hline Glottic & $0.32(0.15,0.70)$ & $0.005^{*}$ & $0.29(0.13,0.68)$ & $0.004 * *$ \\
\hline Subglottic & $0.99(0.13,7.67)$ & 0.989 & $1.30(0.16,10.38)$ & 0.804 \\
\hline Subglottic & Reference & & Reference & \\
\hline Glottic & $0.28(0.04,2.48)$ & 0.277 & $0.18(0.02,1.49)$ & 0.112 \\
\hline Tumor differentiation & & $0.009 *$ & & 0.095 \\
\hline T classification & $1.37(0.88,2.12)$ & 0.162 & & 0.510 \\
\hline $\mathrm{N}$ classification & $1.83(1.16,2.88)$ & $0.019 *$ & & 0.224 \\
\hline Clinical stage & $1.52(0.97,2.39)$ & $0.068 *$ & & 0.591 \\
\hline Preoperative radiotherapy & $\mathrm{I} .82(0.43,7.7 \mathrm{I})$ & 0.416 & & \\
\hline Preoperative chemotherapy & $5.07(1.52,16.92)$ & $0.008^{*}$ & & 0.052 \\
\hline Postoperative radiotherapy & $2.01(0.87,4.62)$ & 0.102 & & \\
\hline Postoperative chemotherapy & $9.40(4.06,21.75)$ & $<0.001 *$ & $7.58(3.11,18.47)$ & $<0.001 * *$ \\
\hline
\end{tabular}

Notes: $* P<0.1, * * P<0.05$ is statistically significant.

Abbreviations: LSCC, laryngeal squamous cell carcinoma; HR, hazard ratio; BMI, body mass index; ASA, American society of Anesthesiology; T classification, tumor classification of tumor, node and metastasis classification of cancer; $\mathrm{N}$ classification, node classification of tumor, node and metastasis classification of cancer.

lung metastasis after laryngeal cancer surgery according to univariable analysis. After multivariable analysis, primary site of cancer and postoperative chemotherapy were the independent risk factors for postoperative pulmonary metastasis in LSCC. $\mathrm{N}$ classification, tumor differentiation and clinical stage of laryngeal cancer have been reported as influencing factors in lung metastasis, ${ }^{22}$ which is consistent with our results. In addition, the primary site of cancer was an independent risk factor that supraglottic laryngeal cancer had a greater tendency to develop into secondary primary lung cancer than glottic cancer, which is similar to findings in previous reports. ${ }^{23}$ Although it seems that subglottic laryngeal cancer may contaminate lower airways more than glottic or supraglottic ones, we could not find a statistical difference in our study.

Many studies have found that postoperative chemotherapy has no survival or recurrence benefit, and further, we found that it might be a risk factor for distant metastasis, lymph node metastasis and overall survival. Possibly, the toxicity of chemotherapeutic drugs leads to patient intolerance. Previous studies have reported that multidrug resistance (MDR) of malignant cells to different chemotherapeutic agents may cause recurrence, metastasis and treatment failure, but detection of MDR genes or proteins is required to confirm this. ${ }^{24}$

We also found that the patients who received a total laryngectomy had a higher risk of recurrence than those who received a partial laryngectomy, and glottic laryngeal cancer had a greater local recurrence tendency than supraglottic laryngeal cancer. Hence, we suspect that patients who received a total laryngectomy had a higher clinical stage or that local recurrence had occurred before they were admitted to our hospital. However, the cause of the relationship needs to be 
Table 3 Univariable and Multivariable Cox Proportional Hazard Models of Local Recurrence After Surgery for LSCC

\begin{tabular}{|c|c|c|c|c|}
\hline & \multicolumn{2}{|c|}{ Univariable Analysis } & \multicolumn{2}{|c|}{ Multivariable Analysis } \\
\hline & HR (95\% Cl) & $P$ value & HR (95\% CI) & $P$ value \\
\hline Age $\geq 60(y r)$ & $0.82(0.59,1.14)$ & 0.245 & & \\
\hline Gender (Female) & $0.90(0.33,2.44)$ & 0.839 & & \\
\hline BMI $\left(\mathrm{kg} / \mathrm{m}^{2}\right)$ & $1.02(0.96,1.07)$ & 0.590 & & \\
\hline Smoking & $1.12(0.76,1.65)$ & 0.579 & & \\
\hline Alcohol intake & $0.55(0.36,0.83)$ & $0.005^{*}$ & & 0.058 \\
\hline ASA & $1.00(0.72,1.39)$ & 0.985 & & \\
\hline Cancer history & $0.58(0.18,1.82)$ & 0.348 & & \\
\hline Opioids (morphine, mg) & $0.99(0.99,1.01)$ & 0.848 & & \\
\hline Types of surgery & $2.86(1.86,4.42)$ & $<0.00 I^{*}$ & $3.13(2.03,4.84)$ & $<0.001 * *$ \\
\hline Neck dissection & $0.92(0.66,1.27)$ & 0.590 & & \\
\hline Intubation & $1.08(0.78, \mathrm{I} .5 \mathrm{I})$ & 0.630 & & 0.595 \\
\hline Anesthesia time & $0.94(0.83,1.07)$ & $0.36 \mathrm{I}$ & & \\
\hline Primary site of cancer & & $0.001 *$ & & $0.003^{* *}$ \\
\hline Supraglottic & Reference & & Reference & \\
\hline Glottic & $3.59(1.89,6.84)$ & $<0.001 *$ & $2.69(1.39,5.21)$ & $0.003 * *$ \\
\hline Subglottic & $3.41(0.94 .12 .40)$ & 0.063 & $2.02(0.55,7.39)$ & 0.290 \\
\hline Tumor differentiation & & 0.140 & & 0.697 \\
\hline T classification & I.I5 $(0.96,1.37)$ & 0.129 & & 0.608 \\
\hline $\mathrm{N}$ classification & & $0.004 *$ & & $0.004 * *$ \\
\hline 0 & Reference & & Reference & \\
\hline I & $0.56(0.30,1.03)$ & 0.063 & $0.61(0.33,1.15)$ & 0.127 \\
\hline 2 & $0.24(0.09,0.64)$ & $0.005^{*}$ & $0.27(0.10,0.75)$ & $0.012^{* *}$ \\
\hline Clinical stage & $1.06(0.89,1.27)$ & 0.498 & & \\
\hline Preoperative radiotherapy & $0.98(0.43,2.21)$ & 0.951 & & \\
\hline Preoperative chemotherapy & $0.51(0.13,2.06)$ & 0.343 & & \\
\hline Postoperative radiotherapy & $0.93(0.61,1.43)$ & 0.750 & & \\
\hline Postoperative chemotherapy & $1.2 \mid(0.62,2.39)$ & 0.574 & & \\
\hline
\end{tabular}

Notes: $* P<0.1, * * P<0.05$ is statistically significant.

Abbreviations: LSCC, laryngeal squamous cell carcinoma; HR, hazard ratio; BMI, body mass index; ASA, American society of Anesthesiology; T classification, tumor classification of tumor, node and metastasis classification of cancer; $\mathrm{N}$ classification, node classification of tumor, node and metastasis classification of cancer.

further analyzed. In addition, a study in Norway reported that supraglottic laryngeal cancer presented more frequent recurrence than glottic laryngeal cancer, ${ }^{25}$ which conflicts with our results. Besides, the finding that patients with $\mathrm{N}$ classification 2 had less risk of local recurrence was contrary to our experience, which could be explained that the advanced $\mathrm{N}$ classification before surgery might receive more complete lymph node dissection.

In our research, the incidence of tracheostomal recurrence was significantly lower than previous reports that range from $3 \%$ to $15 \% .{ }^{26}$ According to other research, the primary site of cancer, preoperative tracheotomy and paratracheal lymph node metastasis are independent risk factors for tracheostomal recurrence. ${ }^{26,27}$ However, we found no independent risk factors for stomal recurrence statistically, which could be explained with the limited sample size that matched by similar propensity scores. We also suspect that the patients who had preoperative tracheostomy has poor disease-free survival, ${ }^{28}$ which would make it more difficult to follow up patients and focus enough on tracheostomal recurrence.

Last but not least, age, clinical stage and postoperative chemotherapy were risk factors for the overall survival whereas orotracheal intubation had no effect on survival rate. The effect of postoperative chemotherapy has been discussed in the previous section. According to a previous report, ${ }^{29}$ age itself may affect medical care, and thus, appropriate treatment is not provided for older patients. A decline in treatment compliance, affected by a progressive loss of stress 
Table 4 Univariable and Multivariable Cox Proportional Hazard Models of Lymphatic Metastasis After Surgery for LSCC

\begin{tabular}{|c|c|c|c|c|}
\hline & \multicolumn{2}{|c|}{ Univariable Analysis } & \multicolumn{2}{|c|}{ Multivariable Analysis } \\
\hline & HR(95\% Cl) & $P$ value & $\operatorname{HR}(95 \% \mathrm{Cl})$ & $P$ value \\
\hline Age $\geq 60(y r)$ & $0.89(0.45,1.74)$ & 0.727 & & \\
\hline Gender (Female) & $0.88(0.12,6.42)$ & 0.898 & & \\
\hline BMI $\left(\mathrm{kg} / \mathrm{m}^{2}\right)$ & $0.85(0.75,0.96)$ & $0.007^{*}$ & & \\
\hline BMI classification $\left(\mathrm{kg} / \mathrm{m}^{2}\right)$ & & 0.774 & & 0.620 \\
\hline $\mid 8.5 \leq \mathrm{BMI}<25$ & Reference & & & \\
\hline $\mathrm{BMI}<18.5$ & $0.80(0.28,2.30)$ & 0.682 & & \\
\hline $\mathrm{BMI} \geq 25$ & $0.7 \mathrm{I}(0.25,2.03)$ & 0.525 & & \\
\hline Smoking & $1.02(0.46,2.28)$ & 0.953 & & \\
\hline Alcohol intake & $1.29(0.63,2.65)$ & 0.490 & & \\
\hline ASA & $0.92(0.47, \mathrm{I} .8 \mathrm{I})$ & 0.806 & & \\
\hline Cancer history & $1.77(0.42,7.37)$ & 0.435 & & \\
\hline Opioids (morphine, mg) & $0.99(0.97,1.00)$ & 0.103 & & 0.061 \\
\hline Types of surgery & $1.25(0.59,2.62)$ & 0.553 & & \\
\hline Neck dissection & $1.12(0.56,2.22)$ & 0.751 & & \\
\hline Intubation & $0.93(0.47,1.84)$ & 0.838 & & \\
\hline Anesthesia time & $0.93(0.72,1.23)$ & 0.629 & & \\
\hline Primary site of cancer & $0.56(0.23,1.13)$ & 0.104 & & 0.237 \\
\hline Tumor differentiation & I.48 $(0.86,2.56)$ & 0.157 & & \\
\hline T classification & $1.20(0.82,1.76)$ & 0.339 & & 0.647 \\
\hline $\mathrm{N}$ classification & $\mathrm{I} .27(0.8 \mathrm{I}, 2.00)$ & 0.302 & & 0.933 \\
\hline Clinical stage & $1.16(0.80,1.68)$ & 0.428 & & 0.270 \\
\hline Preoperative radiotherapy & $2.02(0.62,6.62)$ & 0.244 & & \\
\hline Preoperative chemotherapy & $1.03(0.14,7.54)$ & 0.976 & & \\
\hline Postoperative radiotherapy & $0.78(0.30,2.02)$ & 0.611 & & \\
\hline Postoperative chemotherapy & $5.18(2.25,11.91)$ & $<0.001 *$ & $5.18(2.57,11.91)$ & $<0.00 I^{* *}$ \\
\hline
\end{tabular}

Notes: $* P<0.1, * * P<0.05$ is statistically significant.

Abbreviations: LSCC, laryngeal squamous cell carcinoma; HR, hazard ratio; BMI, body mass index; ASA, American society of Anesthesiology; T classification, tumor classification of tumor, node and metastasis classification of cancer; $\mathrm{N}$ classification, node classification of tumor, node and metastasis classification of cancer.

tolerance, decline in multiple organ systems, high prevalence of comorbid conditions, reduced cognition, and higher prevalence of depression, are also the reasons why elderly patients had poor survival rates. ${ }^{30,31}$ In addition, clinical stage $1 / 2$ and clinical stage $3 / 4$ showed significant differences, but there were no significant difference between them, which indicates that patients in the early stages of disease have higher survival rates than those in advanced stages.

We should objectively evaluate the limitations of these data. First, as a non-randomized, retrospective cohort study, selection bias and incomplete information may exist. Although propensity-score matching was used to balance the differences in baseline characteristics, intrinsic biases may not have been avoided. Second, the regimen and dose of preoperative or postoperative chemotherapy or radiotherapy was unclear, which may affect the accuracy of the comparisons between groups. Additionally, only overall survival was analyzed, while disease-free survival was not assessed, which is also important for patients with laryngeal cancer. Finally, because the follow-up time for some patients was too short and a relatively small number of cases were included in the study, the findings must be interpreted cautiously.

\section{Conclusion}

This retrospective study reveals that orotracheal intubation in laryngectomy does not increase the risk of lung metastasis, local recurrence or overall survival, which suggests that routine anesthesia is relatively safe and does not affect the prognosis of laryngeal cancer patients. Thus, doctors can choose orotracheal intubation or tracheotomy based on the tumor size and patient comfort. However, due to the limitations of this study, prospective, randomized, clinical trials for a larger number of patients are certainly needed. 

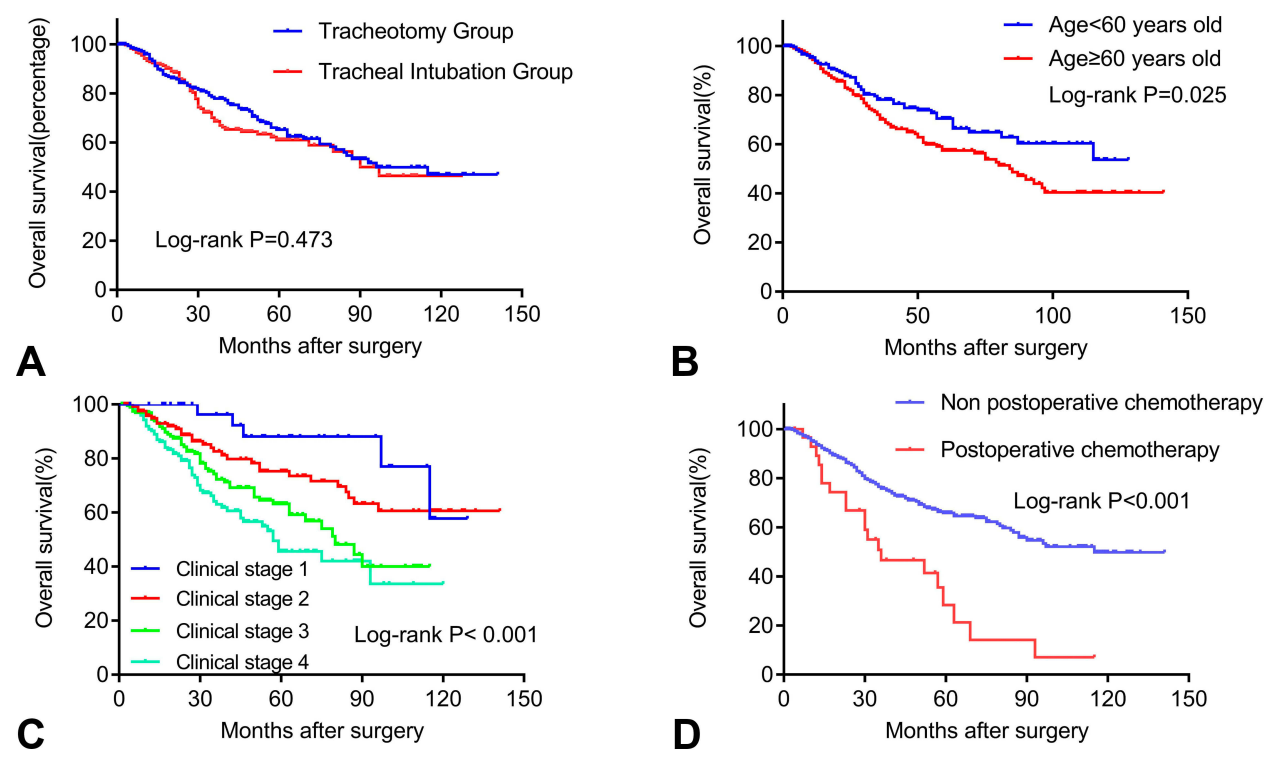

Figure 3 Overall survival related to tracheal intubation (A), age (B), clinical stage (C) and postoperative chemotherapy in LSCC. Log rank test was used to analyze the effects of tracheal intubation, age, clinical stage and postoperative chemotherapy for overall in patients with LSCC. Survival curve of tracheotomy group and tracheal intubation group (A) showed that there is no significant difference in overall survival $(P>0.05)$, but age (B), clinical stage (C) and postoperative chemotherapy (D) showed significance for survival $(P<0.05)$.

Abbreviation: LSCC, laryngeal squamous cell carcinoma.

\section{Abbreviations}

$\mathrm{HR}$, hazard ratio; $\mathrm{CI}$, confidence interval; TNM, tumor, node and metastasis classification; LSCC, laryngeal squamous cell carcinoma; NCCN, National Comprehensive Cancer Network; UICC, Union for International Cancer Control; AJCC, American Joint Committee on Cancer; BMI, body mass index; ASA, American Society of Anesthesiology; MDR, multidrug resistance.

\section{Data Sharing Statement}

All data included in this article are available from the first or corresponding author on a reasonable request.

\section{Ethics Approval and Consent to Participate}

Review of the oncology and anesthesia databases was approved by the committee of Sun Yat-Sen University Cancer Center and the ethics committee approved this consent process and covers the privacy of the participants.

\section{Consent for Publication}

All authors agree to publish this paper and be listed as a co-author of the paper.

\section{Funding}

This study was supported by grant from Guangdong Science and Technology program (2013B021800068).

\section{Disclosure}

The authors report no conflicts of interest in this work.

\section{References}

1. Chen W, Zheng R, Baade PD, et al. Cancer statistics in China, 2015. CA Cancer J Clin. 2016;66(2):115-132. doi:10.3322/caac.21338

2. van Dijk BA, Karim-Kos HE, Coebergh JW, Marres HA, de Vries E. Progress against laryngeal cancer in The Netherlands between 1989 and 2010. Int J Cancer. 2014;134(3):674-681. doi:10.1002/ijc.28388

3. Steuer CE, El-Deiry M, Parks JR, Higgins KA, Saba NF. An update on larynx cancer. CA Cancer J Clin. 2017;67(1):31-50. doi:10.3322/ caac. 21386

4. Miller KD, Siegel RL, Lin CC, et al. Cancer treatment and survivorship statistics, 2016. CA Cancer J Clin. 2016;66(4):271-289. doi:10.3322/caac. 21349

5. Brandstorp-Boesen J, Sørum Falk R, Boysen M, Brøndbo K. Impact of stage, management and recurrence on survival rates in laryngeal cancer. PLoS One. 2017;12(7):e0179371. doi:10.1371/journal.pone.0179371

6. Huang Y, Pan L, Helou K, et al. Mechanical ventilation promotes lung metastasis in experimental $4 \mathrm{~T} 1$ breast cancer lung-metastasized models. Cancer Manag Res. 2018;10:545-555. doi:10.2147/CMAR.S142650

7. Sprung J, Scavonetto F, Yeoh TY, et al. Outcomes after radical prostatectomy for cancer: a comparison between general anesthesia and epidural anesthesia with fentanyl analgesia: a matched cohort study. Anesth Analg. 2014;119(4):859-866. doi:10.1213/ANE.0000000 000000320 
8. Dąbrowska AM, Słotwiński R. The immune response to surgery and infection.Cent. Eur J Immunol. 2014;4:532-537. doi:10.5114/ ceji.2014.47741

9. Jaura AI, Flood G, Gallagher HC, Buggy DJ. Differential effects of serum from patients administered distinct anaesthetic techniques on apoptosis in breast cancer cells in vitro: a pilot study. Br J Anaesth. 2014;113:i63-7. doi:10.1093/bja/aet581

10. Özdemir BC, Pentcheva-Hoang T, Carstens JL, et al. Depletion of carcinoma-associated fibroblasts and fibrosis induces immunosuppression and accelerates pancreas cancer with reduced survival. Cancer Cell. 2014;25(6):719-734. doi:10.1016/j.ccr.2014.04.005

11. Yanagawa T, Saito K, Takagishi K. Risk factors for lymphatic metastasis of malignant bone and soft-tissue tumors: a retrospective cohort study of 242 patients. Medicine (Baltimore). 2014;93(27):e225. doi:10.1097/MD.0000000000000225

12. Hosking MP, Warner MA, Lobdell CM, Offord KP, Melton LJ 3rd. Outcomes of surgery in patients 90 years of age and older. JAMA. 1989;261(13):1909-1915. doi:10.1001/jama.1989.03420130077027

13. Austin PC. Optimal caliper widths for propensity-score matching when estimating differences in means and differences in proportions in observational studies. Pharm Stat. 2011;10(2):150-161. doi:10.1002/pst.433

14. Rodrigo JP, Martínez P, Allonca E, et al. Immunohistochemical markers of distant metastasis in laryngeal and hypopharyngeal squamous cell carcinomas. Clin Exp Metastasis. 2014;31:317-325. doi:10.1007/s10585-013-9630-5

15. Lengyel E. Ovarian cancer development and metastasis. Am J Pathol. 2010;177(3):1053-1064. doi:10.2353/ajpath.2010.100105

16. Basha G, Ectors N, Penninckx F, Filez L, Geboes K. Tumor cell implantation after colonoscopy with biopsies in a patient with rectal cancer: report of a case. Dis Colon Rectum. 1997;40(12):1508-1510. doi:10.1007/BF02070721

17. Kim YD, Lee BY, Min KO, Kim CK, Moon SW. Intrapulmonary recurrence after computed tomography-guided percutaneous needle biopsy of stage I lung cancer. J Thorac Dis. 2014;6(7):1004-1006. doi:10.3978/j.issn.2072-1439.2014.06.32

18. Hu JB, Jin M, Chen EG, Sun XN. Lung squamous cell carcinoma metastasizing to the nasopharynx following bronchoscopy intervention therapies: a case report. World J Surg Oncol. 2014;12(1):68. doi:10.1186/1477-7819-12-68

19. Clever D, Roychoudhuri R, Constantinides MG, et al. Oxygen sensing by $\mathrm{T}$ cells establishes an immunologically tolerant metastatic niche. Cell. 2016;166(5):1117-1131. doi:10.1016/j.cell.2016.07.032
20. Gottschalk A, Brodner G, Van Aken HK, Ellger B, Althaus S, Schulze HJ. Can regional anaesthesia for lymph-node dissection improve the prognosis in malignant melanoma? $\mathrm{Br} J$ Anaesth. 2012;109(2):253-259. doi:10.1093/bja/aes 176

21. Saied NN, Helwani MA, Weavind LM, Shi Y, Shotwell MS, Pandharipande PP. Effect of anaesthesia type on postoperative mortality and morbidities: a matched analysis of the NSQIP database. $\mathrm{Br}$ J Anaesth. 2017;118(1):105-111. doi:10.1093/bja/aew383

22. Hoch S, Katabi N, Daniel H, et al. Prognostic value of level IV metastases from head and neck squamous cell carcinoma. Head Neck. 2016;38(1):140-146. doi:10.1002/hed.23861

23. Milano MT, Peterson CR 3rd, Zhang H, Singh DP, Chen Y. Second primary lung cancer after head and neck squamous cell cancer: population-based study of risk factors. Head Neck. 2012;34:1782-1788.

24. Yu P, Du Y, Yang L, Fan S, Wu J, Zheng S. Significance of multidrug resistance gene-related proteins in the postoperative chemotherapy of gastric cancer. Int J Clin Exp Pathol. 2014;7(11):7945-7950.

25. Brandstorp-Boesen J, Sørum Falk R, Folkvard Evensen J, Boysen M, Brøndbo K. Risk of recurrence in laryngeal cancer. PLoS One. 2016;11(10):e0164068. doi:10.1371/journal.pone.0164068

26. Imauchi Y, Ito K, Takasago E, Nibu K-I, Sugasawa M, Ichimura K. Stomal recurrence after total laryngectomy for squamous cell carcinoma of the larynx. Otolaryngol Head Neck Surg. 2016;126 (1):63-66. doi:10.1067/mhn.2002.121515

27. Halfpenny W, McGurk M. Stomal recurrence following temporary tracheostomy. J Laryngol Otol. 2001;115(03):202-204. doi:10.1258/ 0022215011907190

28. Birkeland AC, Rosko AJ, Beesley L, et al. Preoperative tracheostomy is associated with poor disease-free survival in recurrent laryngeal cancer. Otolaryngol Head Neck Surg. 2017;157(3):432-438. doi:10.1177/0194599817709236

29. Linn BS, Robinson DS, Klimas NG. Effects of age and nutritional status on surgical outcomes in head and neck cancer. Ann Surg. 1988;207(3):267-273. doi:10.1097/00000658-198803000-00008

30. Sharma A, Madan R, Kumar R, et al. Compliance to therapy-elderly head and neck carcinoma patients. Can Geriatr J. 2014;17(3):83-87. doi:10.5770/cgj.17.101

31. Kim H, Kim SD, Shim YJ, et al. Is there any age cutoff to treat elderly patients with head and neck cancer? comparing with septuagenarians and octogenarians. J Korean Med Sci. 2016;31 (8):1300-1306. doi:10.3346/jkms.2016.31.8.1300

\section{Publish your work in this journal}

Cancer Management and Research is an international, peer-reviewed open access journal focusing on cancer research and the optimal use of preventative and integrated treatment interventions to achieve improved outcomes, enhanced survival and quality of life for the cancer patient.
The manuscript management system is completely online and includes a very quick and fair peer-review system, which is all easy to use. Visit http://www.dovepress.com/testimonials.php to read real quotes from published authors. 